\title{
Study of the Effect of the Dissected Length and Diameter of Perforators and the Angle of Rotation on Blood Flow in the Radial Artery Perforator-Based Propeller Flaps
}

\author{
MOHAMMED S. BENDARY, M.Sc.*; SALAH NASSER M. AFIFI, M.D.**; HOSSAM M. SAKR, M.D.***; \\ HANY S. MAHMOUD, M.D.** and ADEL HUSSEIN S. AMR, M.D.** \\ The Department of Plastic \& Reconstructive Surgery*, Al-Ahrar Teaching Hospital in Zagazig, \\ Plastic, Burn \& Maxillofacial Surgery Department** and Radiology Department***, Ain-Shams University
}

\begin{abstract}
Background: Soft tissue defects in the hand can result from a varietyof mechanisms including trauma, infection, and malignant tumors. Propeller flaps have become an appealing option for coverage of a large range of defects. The aim of this study is to determine the effect of dissected length of the perforator and its diameter and the angle of rotation or twisting of the flap on the blood flow in this chosen perforator and the flap vascularity.
\end{abstract}

Methods: Thirty cases of skin and soft tissue defects of the hand and wrist were reconstructed with a perforator-based propeller flap from the radial artery in the period from May 2016 to November 2019. The age of patients ranged from 15 to 60 years. The defects were on the dorsal or palmer aspect of the hand and wrist. We evaluated the viability of the flap,blood velocity and flow of the flap, survived area of the flap according to length and diameter of the chosen perforator and the angle of rotation of the flap.

Results: There is a positive correlation between the perforator length, diameter and the survived area of the flap with resultant increase of post-operative velocity and blood flow of the flap. Also, the survived area of the flap is increased with less twisting of the flap and vice versa.

Conclusion: The radial artery perforator based propeller flap is a reliable treatment option for the skin and soft tissue defect of the hand and wrist.

Key Words: Radial artery - Propeller flap - Hand and Wrist.

\section{INTRODUCTION}

Soft tissue defects in the hand can result from a variety of mechanisms including trauma, infection, and malignant tumors. Reconstructive surgeons who encounter these conditions must account for the unique requirements and challenges of soft tissue coverage specific to the hand. The optimal soft tissue reconstruction protects against the development of contractures and facilitates tendon and joint mobility, while maintaining durability and sensibility of the hand. This is particularly true in situations where soft tissue coverage is required [1].
Several reconstructive procedures and their modifications have evolved to provide the ideal soft tissue coverage of the hand. Conventionally, these included a range of options of primary wounds closure, skin grafts, local flaps, distant flaps, and micro-vascular free tissue transfer [2].

Combining the concept of propeller flaps and perforator based flaps, Hallock in 2006 reported a fasciocutaneous flap based on isolated perforating vessel and was rotated $180^{\circ}$ on an eccentric pivot point. The surgical technique and application of the perforator propeller flaps was extensively explained by Teo in 2006 [3]. Propeller perforator flaps have a good vascular pedicle and can yield to wide mobilization and rotation; their harvest is fast and easy without microsurgical anastomosis. However, good patient selection, accurate preoperative planning, and meticulous dissection technique are essential to minimize complications [4].

\section{PATIENTS AND METHODS}

This prospective study was conducted in AinShams University Hospitals, Plastic, Burn and Maxillofacial Surgery Department. Inclusion criteria were patients with the age from 15 to 60 years with acute or chronic soft tissue defects of the hand and wrist due to trauma, post burn deformity and post tumor resection. The patients excluded from the study were with the age under 15 or above 60 years or due to presence of severe comorbiditiesas uncontrolled DM, peripheral vascular disease or mental affection.

Between May 2016 and November 2019, thirty patients with soft tissue defects of the hand and wrist were admitted for reconstruction with radial artery perforator propeller flaps. All were males, their age ranged from 16 to 56 years. Of these 
defects, twenty one patient had a trauma and nine patients had a post burn contracture. The size of the skin defect ranged from $2 \times 2 \mathrm{~cm}$ to $8 \times 5 \mathrm{~cm}$. We evaluated the viability of the flap, blood velocity and flow of the flap, survived area of the flap according tothe length and diameter of the chosen perforator and the angle of rotation of the pedicle.

\section{Surgical technique:}

\section{Pre-operative Doppler:}

Before the operation, mapping of the radial artery perforators by color duplex US using GE logiq p7 US machine using linear vascular probe 7-11 MHZ and selection of the most suitable perforator. It is selected based on: The caliber, pulsatility, proximity to the defect, course and orientation, number and caliber of accompanying veins. Accurate measurement of the perforator length, diameter and the blood flow by color duplex imaging. Flow volume is calculated by multiplying the cross section area of the perforator by the velocity. Informed consent and Photography of the defect were performed.

\section{Pre-operative marking (Fig. 1):}

Radial artery, radial styloid process and the site of chosen perforator were marked. Flap dimensions was delineated regarding defect size as we measure distance from the most distal point of the defect up to site of the perforator to detect the length of the flap and measuring diameter of the defect to detect the width of the flap.

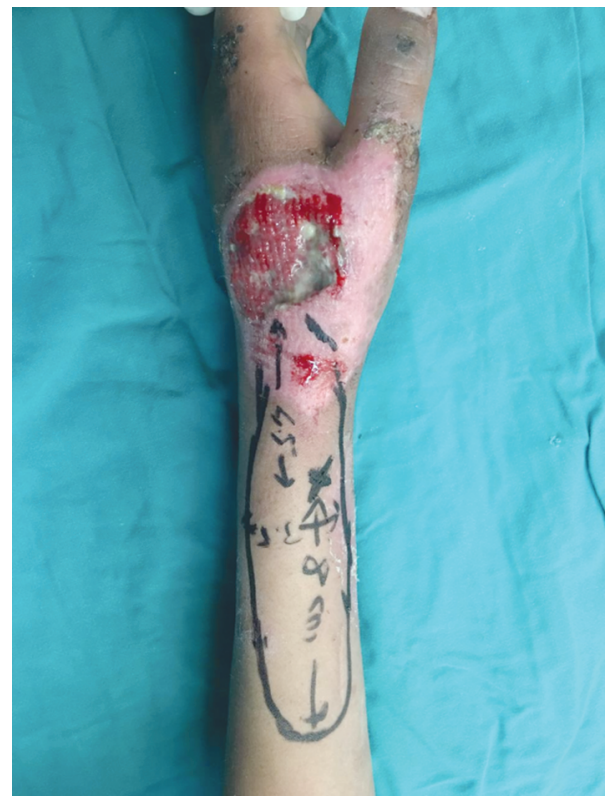

Fig. (1): Pre-operative marking of the perforator and flap dimensions.

Anesthesia:

General anesthesia was used in all patients.

\section{Tourniquet:}

We used a pneumatic tourniquet for all patients, inflating it up to $(250-300 \mathrm{mmHg})$ with partially exsanguinated extremity as it eases the identification of the perforators.

\section{Operative technique:}

We go directly to the preoperative marked perforator starting dissection proximal to site of marking to detect it. Dissection of the perforator using loupe magnification (x 4), to the maximum length up to the site of exit from the main radial artery (which should be measured by caliper and angle of rotation on radial artery), dissecting fascia around the perforator leaving a small part of soft tissue around it. The flap is then dissected all around starting from the ulnar side based on the perforator and surrounding venae comitantes. We confirm our measurements with the Doppler US data (perforator length, diameter and angle of rotation). Cephalic vein was ligated and superficial radial nerve was preserved in all cases.

Rotation of the flap on the site of the defect was done, the direction of the rotation was with the least twist of the perforator. Donor site closure either directly or by STSG, soft dressing with wrist splint.

\section{Post-operative care:}

Limb splinting, the patient received IV antibiotics and analgesics for 3 days post-operatively then oral antibiotics and analgesics and antiedematous drugs for 7 days.

Monitoring for flap viability with measuring the blood flow in the perforator at 24 hours P.O., using the same $\mathrm{CD} / \mathrm{US}$.

Follow-up by clinical assessment (color - temperature - capillary refilling) every 2 hours for 1 st 48 hours, repeated follow-up (twice daily) till changing 1 st dressing of donor site at day 5 then follow-up every 3 days for next 2 weeks then every week for next 3 weeks.

\section{Evaluation of the technique:}

Flap viability by Clinical assessment (color temperature - capillary refilling - pinprick test if needed), Color duplex imaging after 24 hours postoperative for measurement of average blood flow and blood velocity through the perforator (feeding vessel of the flap). Occurrence of complications and the need for further operative procedures.

\section{RESULTS}

Thirty distally based radial artery perforator propeller flaps were used for coverage of hand and 
wrist defects in the period from May 2016 to November 2019. All the 30 patients were male, and their age ranged from 16 to 56 years. Of the 30 flaps, 21 flaps were performed to cover hand defect after trauma (70\%) and 9 for post burn reconstruction $(30 \%)$.

The Doppler US pre-operative measurements, findings were as follow, perforator length was 1,6-3,7mm (Diagram 1), diameter $0.5-1.7 \mathrm{~mm}$ (Diagram 2).

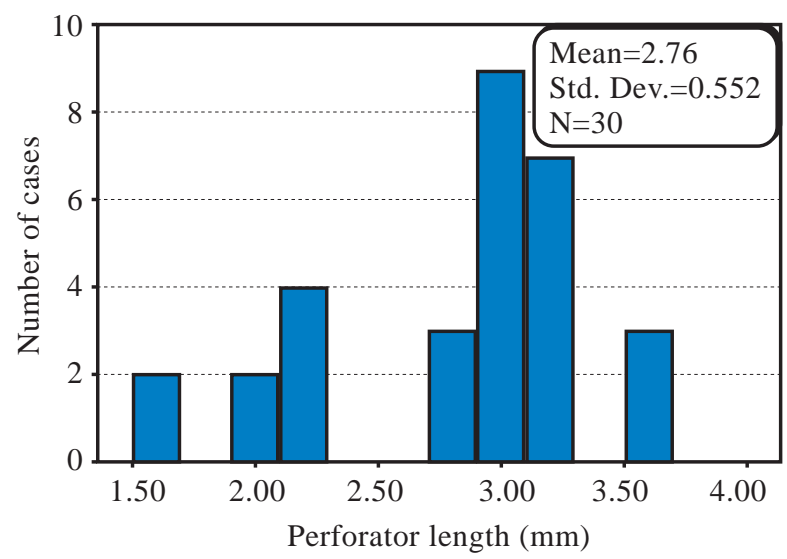

Diagram (1): Frequency of the perforator length (mm).

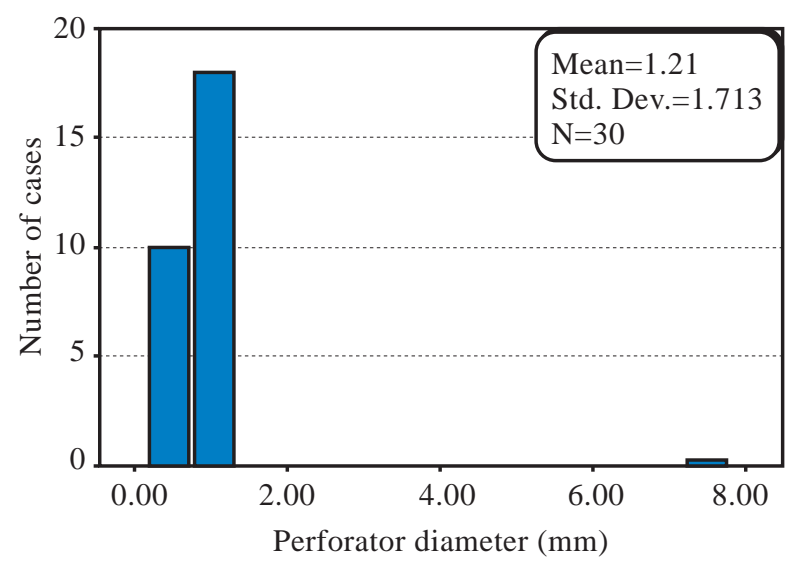

Diagram (2): Frequency of the perforator diameter (mm).

Of our 30 cases, 26 cases with flap rotation $180^{\circ}(86,7 \%), 1$ case with flap rotation $120^{\circ}(3,3 \%)$ and 3 cases with flap rotation $90^{\circ}(10 \%)$ (Table 1$)$.

Table (1): Degree of flap rotation in the studied patients:

Table (1): Shows that $86.7 \%$ of the studied patients had 180 degree of flap rotation while $10.0 \%$ and $3.3 \%$ had 90 and 120 degrees of flap rotation respctively.

\begin{tabular}{cll}
\hline \multirow{2}{*}{$\begin{array}{c}\text { Degree of } \\
\text { flap rotation }\end{array}$} & \multicolumn{2}{c}{$(\mathrm{n}=30)$} \\
\cline { 2 - 3 } & No. & \multicolumn{1}{c}{$\%$} \\
\hline 90 degree & 3 & 10.0 \\
120 degree & 1 & 3.3 \\
180 degree & 26 & 86.7 \\
\hline
\end{tabular}

24 hours post-operative, we measured the postoperative velocity that was found to be ranged from $7.8-14 \mathrm{~cm} / \mathrm{min}$, and the post-operative average flow ranged from $7.4-11.5 \mathrm{ml} / \mathrm{min}$. Average operative time for raising the flap was ranged from 60-85 minutes.

For those flaps that rotated $180^{\circ}$ ( 26 cases), the defect areas were ranged from $4-40 \mathrm{~cm}^{2}$ with raised flap dimensions (from the site of chosen perforator to the most distal part of the defect) were ranged from $15-110 \mathrm{~cm}^{2}$, the survived areas of the flap were ranged from $0-110 \mathrm{~cm}^{2}$.

For the flap that rotated $120^{\circ}$ ( 1 case), the defect area was ranged from $6 \times 4 \mathrm{~cm}$ with raised flap dimensions (from the site of chosen perforator to the most distal part of the defect) were $13 \times 4 \mathrm{~cm}$, the whole flap was survived.

For those flaps that rotated $90^{\circ}$ ( 3 cases), the defect areas were ranged from $12-25 \mathrm{~cm}^{2}$ with raised flap sizes were $21-75 \mathrm{~cm}^{2}$. The whole flaps were survived completely.

Regarding complications of radial artery perforator-based propeller flaps in the studied patients, out of the 30 patients $53 \%$ of them had no complications (16 cases: 12 flaps rotated $180^{\circ}, 1$ flap rotated $120^{\circ}$ and 3 flaps rotated $90^{\circ}$ ), $26.8 \%$ of them had partial flap loss ( 8 cases), $13.4 \%$ of them had total flap loss due to venous congestion (4 cases), and $6.8 \%$ of them had wound dehiscence ( 2 cases), (Diagram 3). These flaps were managed by skin graft in 8 patients, flap advancement in 2 patients $\&$ the remaining 4 wounds were healed by secondary intention.

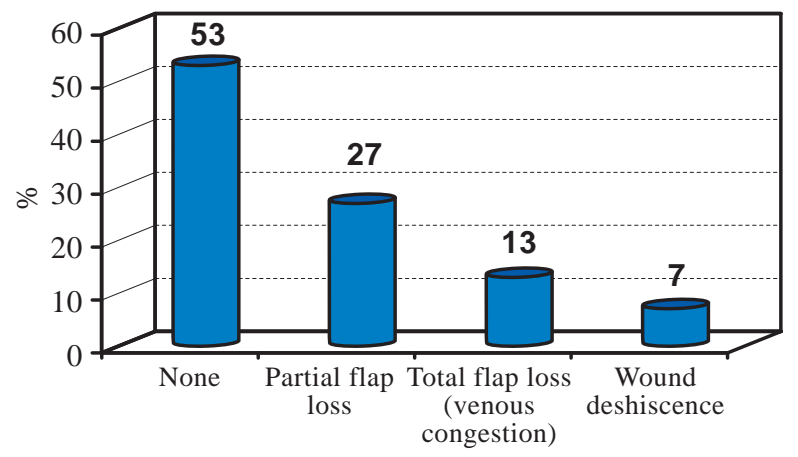

Diagram (3): Complications of the flap.

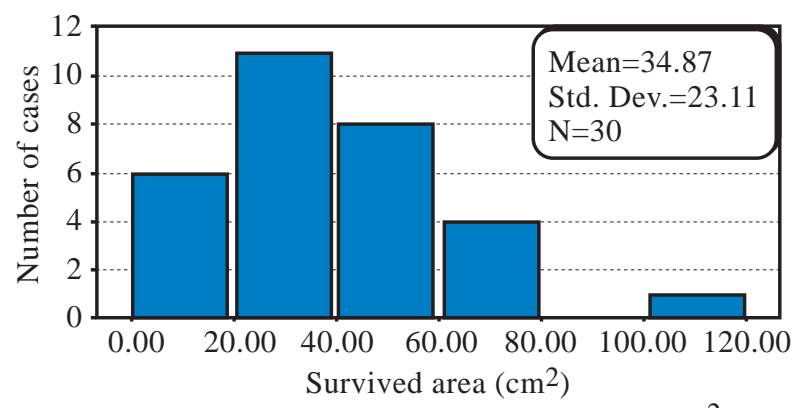

Diagram (4): Frequency of the survived area $\left(\mathrm{cm}^{2}\right)$. 
We found a positive correlation between the perforator length, diameter and the survived area of the flap with resultant increase of post-operative velocity and blood flow of the flap. Also, the survived area of the flap is increased with less twisting of the flap and vice versa as shown in Table (2) and Diagrams $(5,6,7)$.

Table (2): This table shows that there were statistical significant correlations between Survived area of the flap and some variables in the studied patients. Survived area of the flap was positively correlated with Perforator length, perforator diameter, Post-operative velocity and average flow. On other hand Survived area of the flap was negatively correlated with the degree of flap rotation.

\begin{tabular}{lll}
\hline Variables & $r$ & $p$ \\
\hline Age & -0.05 & 0.8 \\
Defect size & 0.13 & 0.5 \\
Perforator length & 0.40 & $0.02(\mathrm{~S})$ \\
Perforator diameter & 0.41 & $0.02(\mathrm{~S})$ \\
Postoperative velocity & 0.45 & $0.01(\mathrm{~S})$ \\
Postoperative average flow & 0.42 & $0.02(\mathrm{~S})$ \\
Degree of flap rotation & -0.60 & $0.001(\mathrm{~S})$ \\
* $r$-correlation coefficient - normal value $(0-1)$ that means positive correlation, value equal or less than \\
$\quad$ - 2 means negative correlation). $(p-p$-value, if less than 0,05 means be significant $(\mathrm{s})$.
\end{tabular}

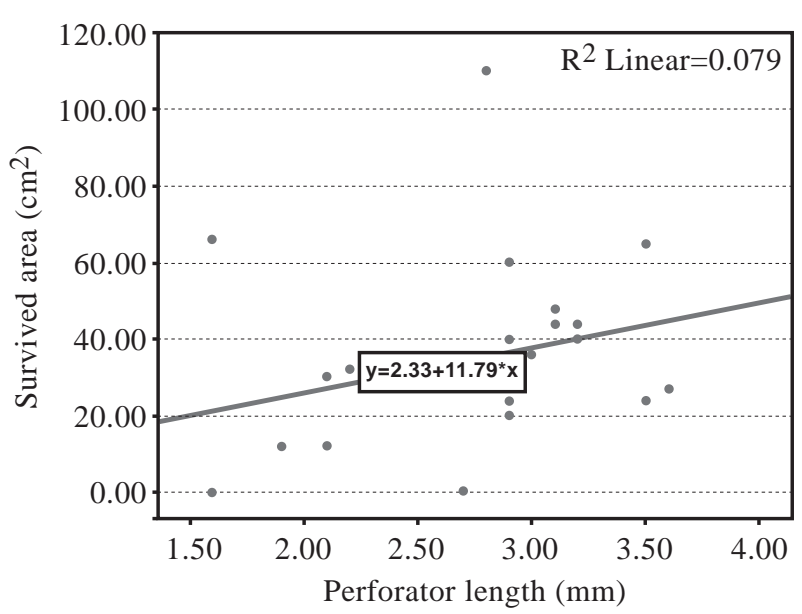

Diagram (5): Shows the positive correlation between the perforator length and the survived area of the flap (increased surface area of the survived flap with increased perforator length).

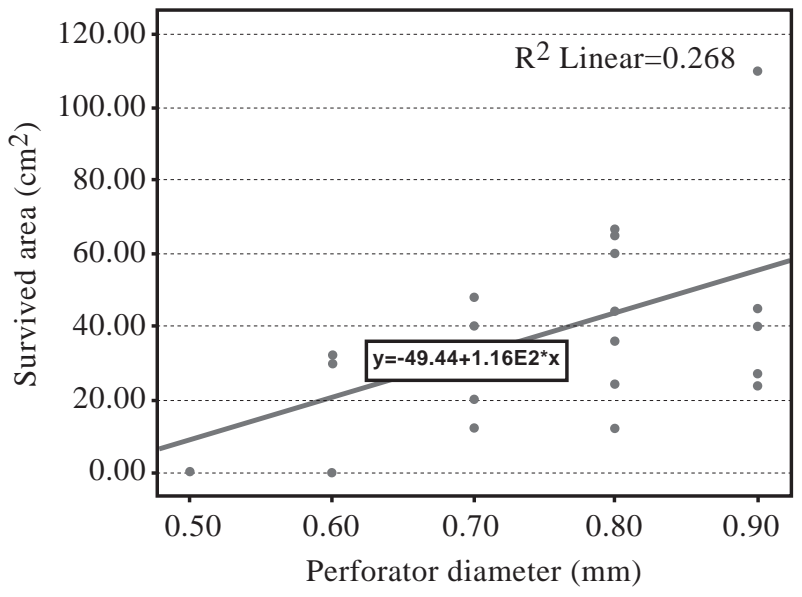

Diagram (6): Shows the positive correlation between the perforator diameter and the survived area of the flap (increased surface area of the survived flap with increased perforator diameter).

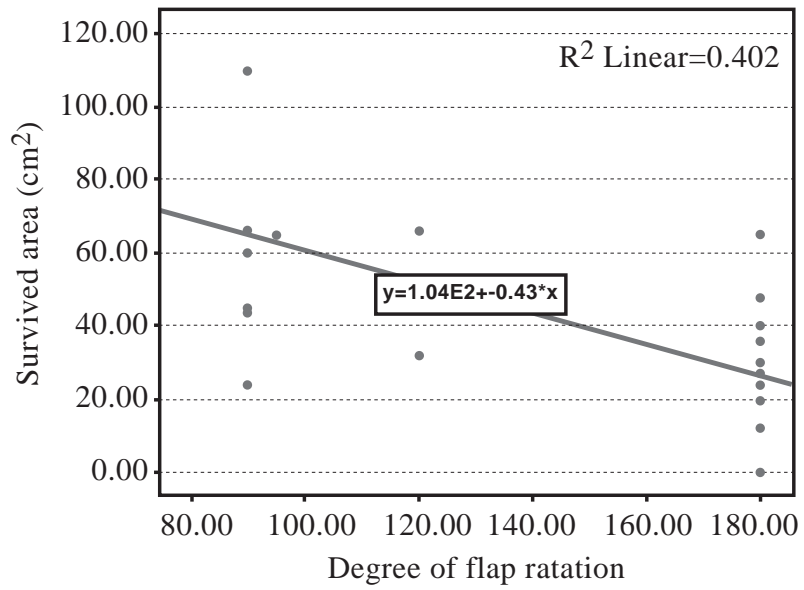

Diagram (7): Shows the negative correlation between the degree of flap rotation and the survived area of the flap (decreased surface area of the survived flap with increased degree of flap rotation). 
Case Reports:

Case (1): Male patient, 24 years old with dorsal hand defect $4 \times 4 \mathrm{~cm}$ (A). RAPPF was raised with a perforator length $3.5 \mathrm{~mm}$ and diameter $0.8 \mathrm{~mm}(\mathrm{~B})$, Flap dimensions was $14 \times 5 \mathrm{~cm}(\mathrm{C})$, The flap 1.5 months PO indicating that $(13 \times 5 \mathrm{~cm})$ of the flap was survived (D).

Case (2): Male patient, 55 years old with dorsal hand defect $2 \times 2 \mathrm{~cm}(\mathrm{~A})$. RAPPF was raised with aperforator length $3.6 \mathrm{~mm}$ and diameter $0.9 \mathrm{~mm}$ (B), Flap dimensions was $10 \times 3 \mathrm{~cm}(\mathrm{C})$, The flap 2 months PO), $(9 \times 3 \mathrm{~cm})$ of the flap was survived (D).
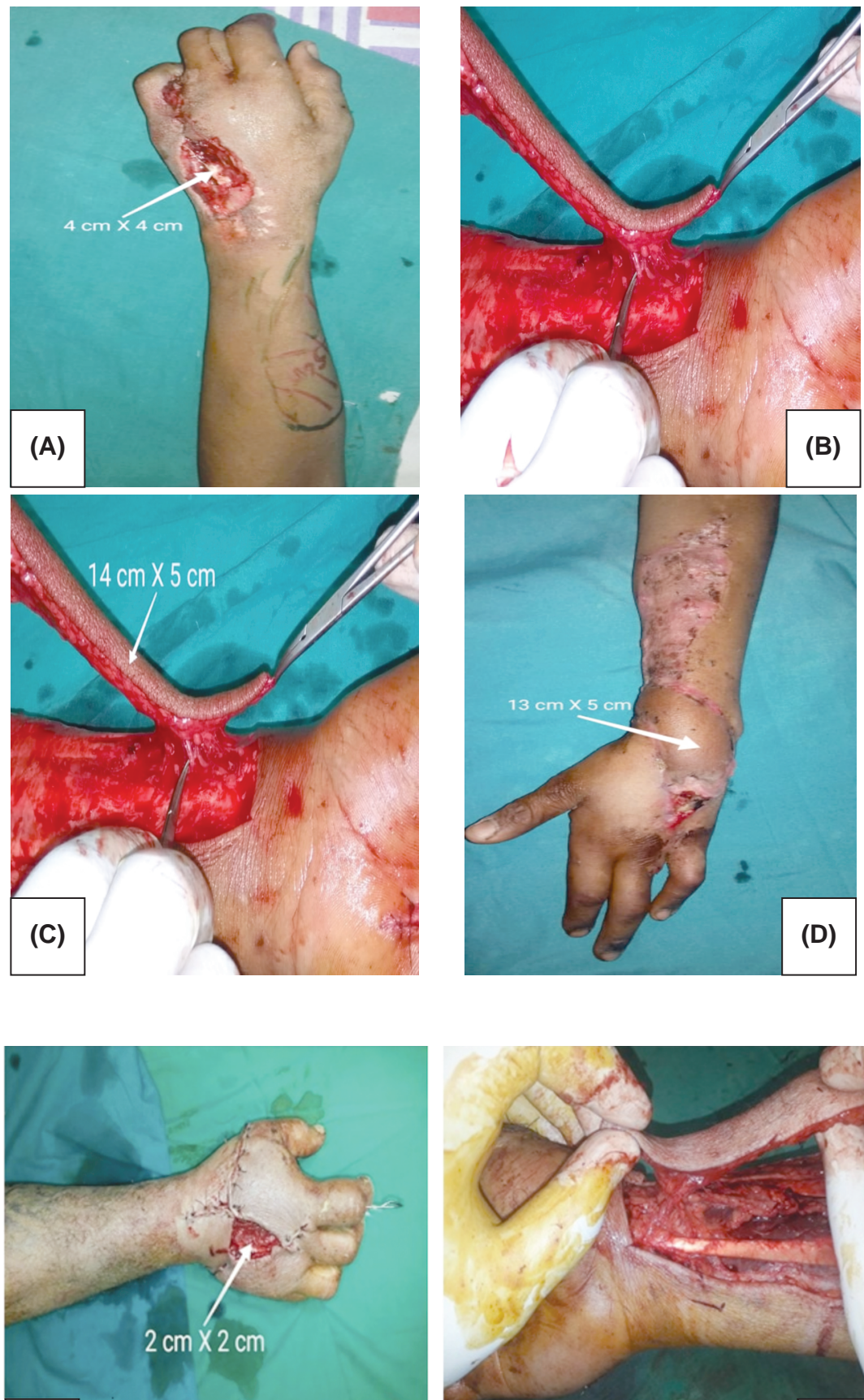

(A)
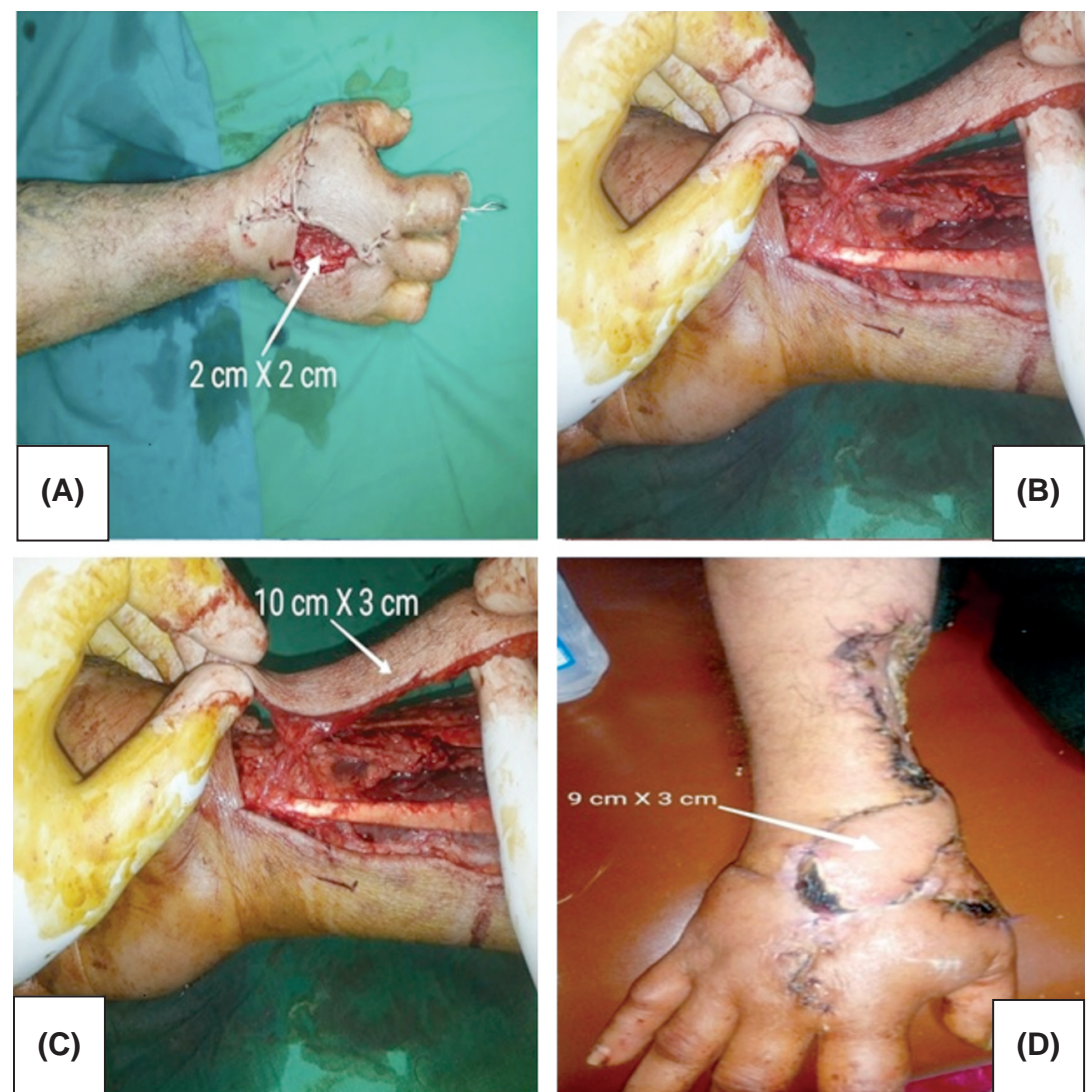


\section{DISCUSSION}

The perforators of the upper extremity are generally shorter in length as compared to those of the lower extremity. Teo (2010) [5] reported that one of the potential limitations to the wider application of the propeller flaps, especially in the distal forearm is the relatively short pedicle, which does not tend to withstand extreme $\left(180^{\circ}\right)$ rotation so well. Even though the pedicle length and diameter of the upper extremity perforators is less as compared to those of the lower extremity, so is the thickness of the skin and fascia which is transferred on the perforator. The major drawback of the perforator-based propeller flap is that the perforator must be intentionally twisted to allow the flap to rotate.

To minimize the effect of perforator twisting on flap survival, some investigators [6,7] advised that flap rotation must be attempted from both sides, and rotation resulting in minimal twist is selected.

Ono et al., (2011) [8] reported that an empty vessel is more susceptible to kinking as compared to a vessel with flow, and they attempted clockwise and counterclockwise rotation of flap to select the direction of rotation before release of the tourniquet. When a rotation has been selected, they put the flap back in its native position. They do the actual rotation after release of the tourniquet. However, when a rotation is performed, one of the veins accompanying the perforator gets kinked, and the other one opens up; and unless the veins are filled it is difficult to determine the better direction of rotation.

We rotate the flaps clockwise and counterclockwise after the release of tourniquet with a couple of minute's interval between the two rotations to prevent spasm to the perforator. The direction causing the least torsional effects is selected.

In our study the defects dimensions ranged from $2 \times 2 \mathrm{~cm}$ to $8 \times 5 \mathrm{~cm}$. The most suitable perforator was selected according to the Doppler U/S study based on its length and diameter.

(Hayashi, et al., 2015) [9] used near-infrared fluorescence angiography with indocyanine green (ICG) to identify the position of the perforator as the vascularity of the flap could also be checked intra-operatively through ICG angiography. Also, (Saint-Cyr, et al., 2009) [10] have mapped out the territory perfused by a single perforator by carrying out static and dynamic dye injection studies in fresh cadavers.
Weused Doppler U/S pre-operatively for mapping and perforator selection, post-operatively for measuring post-operative velocity and average blood flow. We consider the Doppler US is an easy, accurate and reliable method to identify the perforator and to study flap vascularity.

We observed that the common perforators were present within $3-4 \mathrm{~cm}$ from styloid radius. (Koshima, et al.,1995) [11]. Reported that two large perforators can be also found within $2 \mathrm{~cm}$ proximal to the radial styloid. Other numerous but smaller perforators can be found between 2 and $7 \mathrm{~cm}$ above the radial styloid.

We were able to achieve primary closure of the donor area in two cases only, the other cases needed skin grafting. This was related to the defect size and flap dimensions.

Regarding incidence of complications inour patients, $26.8 \%$ had partial flap loss ( 8 cases), 4 of them needed skin grafting and the other 4 healed with 2 ry intention. Total flap loss occurred in 4 cases $(13.4 \%)$ most probably due to venous congestion, these patients were managed by skin graft, wound dehiscence occurred in 2 patients $(6.8 \%)$ that healed by 2ry intention. Successful outcomes without any complications was reported in 16 cases $(53 \%)$.

This high rate of complications was due to venous congestion, as it occurred only in the flaps rotated $180^{\circ}$. This was found to be similar to other studies by (Ono et al., 2011) and (Panse and Sahasrabudhe, 2014) [12] that reported similar results and complications at their studies.

To reduce the risk of vascular complications due to torsion and buckling of the pedicle, Wong et al., 2007 [6] suggested that a perforator of $1 \mathrm{~mm}$ diameter should be dissected for a length of at least $3 \mathrm{~cm}$. We studied the effect of the perforator length and diameter and the degree of rotation of the flap on the blood flow and viability of the flap by measuring the post-operative velocity and average blood flow. We concluded that there is a positive correlation between the perforator length (decrease the perforator kinking with increased perforator length), diameter and the survived area of the flap with simultaneous increased post-operative velocity and post-operative average blood flow. So, the survived area of the flap was increased with less twisting of the flap and vice versa.

After reviewing the CDI of the 26 flaps that rotated $180^{\circ}$, we can safely conclude the following: We can raise safe flap in the following situations: 
- With perforator length $(2,9-3,6) \mathrm{mm}$, perforator diameter $(0,7-0,9) \mathrm{mm}$, we can raise flap within range $(13 \times 5) \mathrm{cm}$, with post-operative velocity up to $(12,2 \mathrm{~cm} / \mathrm{sec}$.) And post-operative blood flow-up to $(11,2 \mathrm{ml} / \mathrm{min}$.).

- With perforator length $(2,1-2,8) \mathrm{mm}$, perforator diameter $(0,6-0,7) \mathrm{mm}$, we can raise flap within range $(8 \times 4) \mathrm{cm}$, with post-operative velocity up to $(11,9 \mathrm{~cm} / \mathrm{sec}$.) And post-operative blood flow up to $(10,9 \mathrm{ml} / \mathrm{min}$.).

- With perforator length $(1,5-2) \mathrm{mm}$, perforator diameter $(0,5-0,6) \mathrm{mm}$, we can raise flap within range $(2 \times 2) \mathrm{cm}$, with post-operative velocity up to $(10 \mathrm{~cm} / \mathrm{sec}$.) And post-operative blood flow up to $(10 \mathrm{ml} / \mathrm{min}$.).

\section{Conclusion:}

After reviewing the CDI of our 30 flaps performed, we can safely conclude that the increase of the length and diameter of the perforator of the propeller flaps increases the survival of the flaps and on the other hand the increase in the degree of flap rotation compromises flap vascularity.

However, this option for hand defects and soft tissue reconstruction still needs more work to eliminate the relatively high rate of complications.

\section{REFERENCES}

1- Janis J.E., Kwon R.K. and Attinger C.E.: The new reconstructive ladder: Modifications to the traditional model. Plastic and Reconstructive Surgery, 127: 205S-212, 2011.

2- Friedrich J.B., Katolik L.I. and Vedder N.B.: Soft tissue reconstruction of the hand. J. Hand Surg. Am. Jul-Aug., 34 (6): 1148-1155, 2009.
3- Teo T.C.: "Perforator local flaps in lower limb reconstruction", Cirugia Plastica Ibero-Latinoamericana, Vol. 32, No. 4, pp. 15-292, 2006.

4- Arpa S.D., Cordova A., Pignatti M. and Moschella F.: Freestyle and management based on 85 consecutive cases", Plastic and Reconstructive Surgery, Vol. 128, No. 4, pp. 892-906, 2014.

5- Teo T.C.: The propeller flap concept. Clin. Plast. Surg., 37 (4): 615-26, 2010.

6- Wong C.H., Cui F., Tan B.K., Liu Z., Lee H.P. and Lu C.: Nonlinear finite element simulations to elucidate the determinants of perforator patency in propeller flaps. Ann. Plast. Surg., 59: 672-678, 2007.

7- Panse N.S., Bhatt Y.C. and Tandale M.S.: What is safe limit of the perforator flap in lower extremity reconstruction? Do we have answers yet? Plast. Surg. Int., 2011: 349-357, 2011.

8- Ono S., Sebastin S.J., Yazaki N., Hyakusoku H. and Chung K.C.: Clinicalapplications of perforator-based propeller flaps in upper limb soft tissue reconstruction. J. Hand Surg. Am., 36: 853-63, 2011.

9- Hayashi A., Yoshizawa H., Tanaka R., Natori Y., Arakawa A. and Mizuno H.: Intraoperative Use of Indocyanine Green Fluorescence Angiography during Distally Based Radial Artery Perforator Flap for Squamous Cell Carcinoma of the Thumb (Plast. Reconstr. Surg. Glob Open 19 February, 3: e310; doi: 10.1097, 2015.

10- Saint-Cyr M., Wong C., Schaverien M., Mojallal A. and Rohrich R.J.: The perforasome theory: Vascular anatomy and clinical implications. Plast. Reconstr. Surg., 124: 1529-44, 2009.

11- Koshima I., Moriguchi T., Etoh H., et al.: The radial artery perforator-based adipofasical flap for dorsal hand coverage. Ann. Plast. Surg., 35: 474-479, 1995.

12- Panse N. and Sahasrabudhe P.: Department of Plastic Surgery, B.J. Government Medical College \& Sassoon Hospital, Pune, Maharashtra, India (Free style perforator based propeller flaps: Simple solutions for upper extremity reconstruction) May 17, IP: 117.195.50.173, 2014. 